\title{
Strategic planning for national knowledge-based development using the SWOT strategic model
}

\author{
Mehdi Jamalinejad $^{\mathrm{a}^{*}}$, Ali Zangiabadi ${ }^{\mathrm{b}}$ and Hamid Reza Varesi ${ }^{\mathrm{b}}$
}

${ }^{a}$ Ph.D Student of Geography and Urban Planning, University of Isfahan, Isfahan, Iran ${ }^{b}$ Associate Professor of Geography and Urban Planning, University of Isfahan, Isfahan, Iran

CHRON I C LE ABSTRACT

\begin{tabular}{l}
\hline Article history: \\
Received Decemb \\
Accepted 8 May 2 \\
Available online \\
May 202014 \\
\hline Keywords: \\
Science \\
Technology \\
Innovation \\
Knowledge-based \\
SWOT
\end{tabular}

\section{Introduction}

Knowledge is considered as the most important resource exploited towards competitiveness and development in the present-day, ever-changing economic arena. Indeed, individuals, firms, and regional systems increasingly depend for their survival on their capacity and competence in working *Corresponding author.

E-mail addresses: mehdijamalinejad@yahoo.com (M. Jamalinejad)
Industrialized and rich nations owe much of their development to advances and achievements they have made in science and technology. These assets have not only served as engines powering their advanced economies but have also led to their exponential social growth. Thus, advancements in science and technology may be regarded as indicators of fundamental development in any modern society as it is the knowledge-based society that is in a superior position to address and resolve its basic problems. While Iran has also been taking drastic steps towards its scientific and technological development, decisive measures are yet to be taken toward developing a strategic plan for these development objectives and gaining a comprehensive understanding of its different aspects. Employing an analytic-descriptive approach, the present study aims to develop fundamental strategies for the national scientific and technological development using the SWOT strategic model. The results indicate that the development of infrastructure for access to information networks with a weight of 0.56 ranks first among the strengths while absence of a strategic development plan with a weight of 0.372 ranks first among the weaknesses. IT infrastructure with a weight of 0.608 is found to have the highest weight among the opportunities while the low relevance between educational programs (at both levels of general and higher education) and scientific and innovation requirements is found to rank first with a weight of 0.46 among the threats. Among the most essential strategies that need to be adopted, one can refer to the development of a basic framework for the uniform and need-oriented connectivity and access to IT and the Internet across the nation; creation and development of such knowledge-based systems and facilities as business and technology incubators, science parks, science a\& technology corridors, and innovation clusters aiming at a knowledge-based, dynamic, and developed society; directing efforts at striking a balance between the number of university graduates and the market demands for young educated work force; and maximum involvement of the educated youths in the realization of national development objectives. 
with knowledge resources (Lerro \& Schiuma, 2009). Knowledge, research, and creativity have come to be recognized as prerequisites to innovation and invention (Stefanie Hohn, 2010). Knowledge management (KM) may be defined as the process of creation, dissemination, and application of knowledge for achieving organizational objectives (Akhavan, 2010). However, most firms and organizations launching knowledge management systems fail to have access to adequate information on proper methods to adopt the best approaches to KM (Moffett Sandra, 2003).

Our modern world is characterized by vast changes, increasing complexities, and close competitions with organizations operating in a complex but dynamic environment. As intellectual property in our age fuels the growth engine of a nation, understanding the significance and the value of this intellectual asset makes it more important than ever before (Passerini, 2007); the same also holds true for access to knowledge resources by scientists and their interactions (Lange et al., 2010). Most experts on higher education maintain that educational and academic centers as the principal institutions of teaching and learning, in their attempts to face the challenges of the new millennium, have no way but to transform their respective societies into knowledge-based ones, to create and promote the knowledge-sharing culture, and to employ an efficient KM strategy (Nemati, 2006). According to the Malaysian Government, the essential approach for them to achieve the objectives of commercializable knowledge would involve enhancing the efficiency of academic centers through implementing and employing KM systems (Mohayidin, 2007).

Advances and developments in our world today are based on technologies that are not only promoted and shaped by scientific discoveries but are also made sustainable by them. Technology as the product of developments in modern human civilization has become the basic element in all social and economic transactions and has come to represent the level of progress and power of any society and the major factor that determines a society's superiority over competing ones (Webster, 1991).

It must be mentioned in passing that not all knowledge generated can lead to the creation of a rich, deep-rooted civilization. Suffice it to say that among the myriad of Iranian scientists in the past only a few mastered the type of knowledge that would form or boost a civilization while there were also those who never succeeded to implement ideas that arose from their knowledge. Knowledge and its products can lead to the creation or enhancement of a civilization only when they gain substance in certain effective models; in other words, knowledge that is capable of forming civilizations is itself a specific subfield of human scientific achievement that obeys its own rules and principles. For instance, there have been great achievements made by Iranian scientists in the fields of science and technology over the recent decades. The results of the present study, however, indicate that these efforts have unfortunately suffered a lot from the lack of a holistic and powerful management model. This issue seems to warrant a separate investigation into its different aspects and reasons.

\subsection{Knowledge and its management at the social level}

Knowledge is in one sense the capability to apply information. In this sense, it should enable managers to interpret information and apply it when making decisions (Ahmadi, 2003). Hence, it has been defined as the understanding, awareness, or perception that is gained in the course of time through study, research, observation, and experience. In another sense though, knowledge is the combination and integration of thinking and information, or indeed, a kind of personal interpretation of information based on personal experience, skills, and capacities (Davarpanah, 2005). Knowledge management involves the development, sharing, and application of knowledge in an organization to achieve a sustainable competitiveness. It includes all the intra- and inter-organizational processes, regulations, and methods arising from organizational, cultural, and knowledge infrastructure aimed at the optimal utilization of organizational knowledge. It should ultimately lead to the transformation of individuals' knowledge into organizational knowledge and synergy to enhance competitiveness. 
For knowledge to exhibit its value in a knowledge-based economy, it must be transformed into processes or physical products (e.g., patents, trademarks, and intellectual property or methods, regulations, and innovative or discovery procedures). Capital and human resources, on the other hand, are the most essential elements in developing and protecting knowledge. It will, therefore, be essential to train and foster the human resources for these purposes. However, it is difficult to quantify the potential value of knowledge for human transactions and the knowledge that is created by human transactions and in human networks. Knowledge may only be measured when its hidden, underlying components are made explicit in application. Even so, its undisclosed values, potentials, and aspects remain far more unknown than its outward manifestations. This dual structure is the cause of the great variety in methods and procedures developed/proposed for knowledge management, and especially in the variety of our understanding and assessment of the intellectual property owned by nations and organizations. Moreover, as intellectual property is nowadays regarded as the fuel and the driving force for the progress of any nation state, assessment and understanding the value of their assets in terms of knowledge and intellectual property gains more importance than ever before (Passerini, 2007).

Given the uneven distribution of knowledge resources across the globe, while some may raise questions as to the quantity and quality of academic centers such universities or research institutes, perhaps it would be more reasonable and significant to ask whether and how scientists have access to knowledge resources; how and if they are properly aware of their immediate, local concerns; or if these scientists have any transactions at the local level (Lange et al., 2010).

Knowledge-based development may be viewed in two ways. It may be considered, from one viewpoint, as an asset and stockpile of financial resources generated by educational and technological products, as is usually the case; or from another, it may be regarded as a balance achieved among all the social, cultural, physical, and financial elements in the common value system of a society. Thus, knowledge-based development in an urban environment goes beyond the economic, social, and policy-making boundaries of urban life. In the global economic environment, knowledge-based development involves the capacity of a nation not only to produce, transfer, and apply knowledge but also to utilize the knowledge generated outside the national boundaries for responding to specific, domestic needs. For a knowledge-based development to be realized, relevant mechanisms are needed that facilitate the transfer and circulation of knowledge and information between and among the developing and developed nations. Multi-national knowledge sharing is a concept quite similar and closely related to that of knowledge-based development (Chou \& Passerini, 2009).

\subsection{The Sate of Science and Knowledge in Iran}

Iran did not have any measurable record of scientific products and publications by before the Islamic Revolution of 1979. However, this record as indexed by SCOPUS has ever since risen to 25,829 titles which ranks first on a regional basis (Bayat, 2010). According to the latest statistics by ISI up to the end of January 2012, the number of scientific papers by Iranian scholars amounts to 24,745 which ranks Iran only second to Turkey with 27,612 papers (Sabouri, 2012).

The present paper investigates scientific development in Iran and the need for this kind of development at the national level. As examples of recent developments that have created the infrastructure required for the national scientific development, one can refer to the multitude of graduate programs established across the nation, the variety of scientific and professional societies founded, the many technology incubators and centers of excellence established, the new technologies developed by Iranian scholars, the myriad of scientific publications funded or supported by Iranian universities, the research centers coming into operation over the recent decades, the academic journals authorized and accredited by the two ministries of Science, Research, \& Technology 
(MSRT) and Health and Medical Education along with comparable activities by the Islamic Azad University (Mehrad, 2011; Movahedi, 1999).

As another example, one can mention the Item under the Fourth National Development Plan Act that mandates 3\% of the GDP to be allocated to the advancement of research; this Act has not yet been realized but it will obviously give rise to a leap in scientific and research advancement once it comes into force (the Fourth Economic, Social, \& Cultural Development Plan Act of the Islamic Republic of Iran, 2005 (1384): 46). According to the 2012 ranking by the World Bank Group, Sweden ranked first and Haiti ranked last in terms of knowledge-based economy index (EKI) among 146 countries. According to the same ranking, Iran rose from 95 in 2000 to 94 in 2012. According to another ranking, Iran ranks 45 among 72 nations in terms of access to technology and technological production (www.nationmaster.com). Iran ranks 58 on a global scale in terms of innovation capacity (www.innovationfordevelopmentreport.org). The Fifth National Development Plan of the Islamic Republic of Iran mandates that Iran should rank second as the goal for its IT development index. This is while, other than the landline index, Iran presently falls far behind the first rank in the region with respect to such other IT indices as mobile penetration index, Internet penetration index, and highspeed internet index. Our survey indicates a wide gap between the goals set in the Vision for Iran 2020 Document and the present situation on the ground in terms of e-government and internet bandwidth. Regarding developments in e-government, although Iran has witnessed a growth of 8 point scales on a global scale, the fast development of e-government systems in the regional states has left Iran’s status unchanged between the years 2009 and 2012 (WEF, 2012:201).

\subsection{Background}

It was only recently and immediately after total quality management (TQM) had been conceived and born that knowledge management, and its offspring 'knowledge management systems', appeared on the world scene. KM was initially limited to information systems but, later on, efforts were directed towards organizational development, intellectual property management, and management skills. By the end of the 1990s, social learning, organizational understanding, systematic innovation, and change management were developed as topics of great interest within the field of knowledge management (Seif et al., 2006).

KM existed even before its advent in the 1980s and 1990s as a new approach to management of organizational assets. Other disciplines such as sociology and anthropology had played important roles in investigating and shaping socio-economic development. On the other hand, urban studies and urban planning had focused on cities and urban areas as unit embodiments of development long before the concept of knowledge-based urban development came into existence. Moreover, such other disciplines as geography and statistics had played a pivotal role in paving the way toward developing the concept of knowledge-based cities. As no single discipline is capable of handling the complex nature of knowledge-based societies, adoption of a multi-disciplinary approach has become a prerequisite to shaping knowledge-based development (Carrillo, 2006).

The knowledge-based development approach first appeared in 1995 for the reclamation and renovation of industrial cities in Europe and US through enhancing both human and institutional capacities and capabilities as well as creating environments favorable to innovation, creativity, learning, and change. By development was meant not only economic growth but also all the parameters reflecting human life's sustainability and quality against an international background. This is clearly different from the traditional production-based activities in the former so-called industrial cities. Rather, knowledge-based development lays emphasis on the soft elements such as software, the living human being, and compatibility and assimilation; it, therefore, requires different strategies for it to realize (Wang \& Lihua, 2006). 
While some people admitted the essential role of education extended to all social strata in production and productivity, they attached less importance to education than previous researchers had. Some other studies indicate that commercial data were better proof and evidence of progress and change in science and technology. For instance, Hawkins (2002) reported how innovation clusters had influenced economic growth in the US. Osareh and Ma'refat (2005) investigated the contribution made by Iranian scholars to the global scientific production and found that Iranian researchers had profiled a great record of scientific achievement in recent decades. This is confirmed by the ISI and Medline records that show a rapid increase in contribution by Iranian scholars to development of science and expansion of scientific horizons. To this must be added the numerous papers published in Iranian and non-ISI journals for which we have no exact statistics. Sadeghi and Azarbayejani (2006) conducted a study of the impact of knowledge-based economy on the market demand for work force in Iran. The results indicate a positive, significant and explanatory effect of science and technology impact on demand for work force. In their paper "Toward a Knowledge-Based Police", Ahmadvand and Rohani (2007) discussed the need for strengthening both the capacity for futuristic studies and the management prerequisites, which would include changes in the culture of the scientific community and the transformation of the traits of a commander from those of a 'Police Manager' to those of a 'Police Leader'. Sayyedi et al. (2007) conducted a survey on the feasibility of developing a knowledge-based organizational system in the Shiraz Branch of the Islamic Azad University. They showed that their respondents confirmed the feasibility of developing such a system in their university.

Mansouri (2008) investigated the design process for a scientific community in Iran. He concluded that by before the Iranian society becomes a maturely rational society capable of adopting and implementing its policies, it will be on scientists themselves to assume the role of designing their own scientific community that is both competent and competitive on the international scale. Nowadays, we are witnessing the formation of the foundations for a scientific community in Iran but a long way still needs to be paved before we reach our ultimate goals of a knowledge-based society. In his paper 'The Knowledge-Based City, the Backbone for Innovation', Rashidi (2008) defined knowledge-based city and the associated concepts. Bagheri and Sharafi Jam (2009) maintained that the knowledge gained from experiences with technological development should be replicated and applied to all types of knowledge.

In the first part of their paper, Paya and Kalantarinejad (2010) described the fourth global wave of scientific and technological development. Adopting a critical-rational approach, they investigated in the second part of their study some of the impacts of this wave on human societies and culture. The major emphasis of their philosophical treatise is laid on the options available to modern man in facing the incessant new advances being made in science and technology. In the third section of their paper, they presented a number of lessons learned in policy-making for raising awareness among policymakers in Iran in their efforts to determine the impacts of this fourth development wave on the Iranian society and culture.

Stefanie Hohn (2010) conducted an empirical study on the key factors involved in the success of knowledge-based cities in Germany. They investigated the role played by science and knowledge in German cities. Their comparisons revealed that cities which are more knowledge-based are more successful with greater achievements by $40 \%$ to $50 \%$. In their report on 'The Future of the Knowledge-based City and Economic Development of Melbourne', Austin Ley (2011) evaluated the indicators of economically and scientifically progressive cities.

Yousefinejad Attari and Neishabouri Jami (2012) investigated the implementation of SWOT Tables in science and technology parks and used the fuzzy analytical network process (ANP) to determine the best strategy for achieving the objectives of S\&T parks. In a first phase of their study, they identified the strengths, weaknesses, threats, and opportunities facing S\&T parks and incubators. 
They then defined seven strategies for achieving the objectives of these institutions and employed the multi-criteria decision-making method and network analysis of a fuzzy environment to determine the best strategy. Finally, based on the advantages of each strategy and comparison Tables, the strategy they opted for involved providing support for scientists and their knowledge-based businesses through agreements and MOUs among the Ministry of Science, Research, and Technology (MSRT); the Ministry of Public Health and Medical Education; and financial institutions such as banks.

Bahari et al. (2012) investigated and prioritized the key factors involved in the success of Khorasan Razavi S\&T Park. The factors involved were prioritized in a descending order as follows: support for knowledge-based firms, human resources, technological infrastructure, and development of technology incubators. This prioritization may be used as a guiding principle for managers of S\&T parks and incubators. Hasanpour et al. (2012) investigated the factors involved in the preparedness for implementation of KM by universities. They found that 'support for KM implementation by management' and 'proper knowledge-sharing among members' had the highest priority while 'decentralization' and 'non-officialization' had the lowest. This ranking of the factors involved may help university managers prior to implementation of their knowledge management systems because KM requires prior improvement of a multitude of factors and it will be difficult to handle all these at the same time. Thus, this ranking may be exploited to prioritize and regulate activities while it may also be used to identify the critical success factors.

\section{Methods and materials}

The present research is an analytical-descriptive one that is based on a survey of the available literature on national scientific and strategic development. A comprehensive SWOT analysis is carried out to identify strengths, weaknesses, threats, and opportunities. Questionnaires and interviews with experts are then used to determine the weight of each alternative strategy. These weights are finally combined and analyzed to identify the best approach to knowledge and scientific development in Iran.

\subsection{Strengths, weaknesses, threats, and opportunities determined by SWOT}

The SWOT method was used to identify and to investigate the internal factors (strengths and weaknesses) and external factors (threats and opportunities) involved in knowledge and scientific development in Iran (Wheelen, 1995: 341). This method is commonly used as a tool not only for detecting and characterizing strategic problems but also for identifying relevant approaches and strategies to resolve those problems. Assessments of both internal and external environments were initially carried out to derive a list of possible strengths, weaknesses, opportunities, and threats. Views were then collected from the public, officials, and experts to characterize these traits. Finally, recommendations and relevant strategies were formulated for eliminating or reducing the weaknesses and threats and for strengthening and improving the strengths and opportunities associated with scientific development in Iran.

\subsubsection{The internal factors involved in scientific development in Iran}

Commonly, internal assessment matrices are used to identify the relationships holding among the different aspects and issues, which can then be used to identify solutions (David, 2004). For this purpose, we focused on the three categories of available strategies, performances, and resources, all of which have been classified under the two rubrics of strengths and weaknesses in Table 1 as follows: 
Table 1

Strengths

\begin{tabular}{ll}
\hline & Strengths \\
\hline 1 & Availability of infrastructure for access to information networks (connectivity) \\
2 & Business incubators and S\&T parks established \\
\hline & Availability of young, talented and educated work force \\
5 & Rapid increase in the number of ISI papers \\
6 & Availability of natural resources required for research and scientific production \\
7 & Availability of essential research facilities and equipment \\
\hline & Availability of industry-based research centers \\
\hline 10 & The large number of universities and research institutes \\
11 & Increasing faculty members and researchers in the higher education sector \\
12 & Incentive plans and awards for publishing papers in domestic and international journals \\
\hline 13 & The vast number of academic journals published in Iran \\
\hline
\end{tabular}

\section{Table 2}

\section{Weaknesses}

Weaknesses

1 Lack of strategic plans for the science and technology sector

2 Inadequate importance attached to meritocracy in appointing managers

Precedence of requirements with face value (such as degrees) over real academic competence

Poor relations among public departments and academic centers

Failure to foster a research-based educational system by the Department of Education

Uselessness and infeasibility of most research results

Brain drain

Inadequate number of competent and skilled managers to direct research projects of real value

Low importance attached to the hiring and keeping of efficient and skilled work force

Failure to use international experiences gained during the development of scientific development programs

Lack of proper local and indigenous models for the management of academic centers

Inadequate remuneration for and the low social status of researchers

Lack of an appropriate performance evaluation and surveillance system

Inadequate commercialization of research findings

Predominance of a quantitative over a qualitative attitude to research

Bureaucracy and poor administrative procedures and structure in research centers

Impossibility of cooperation and resource sharing with progressive nations

Nonexistence of an accountable body in charge of national statistics

Inadequate concern for and lack of interest in research activities by the private sector

Excessive emphasis laid on and overestimation of universities for science production

Greater importance given to individual work rather group work

Poor understanding of developments in the surrounding environment

\subsubsection{External factors affecting scientific and knowledge development}

External factors matrices enable strategic planners to make proper assessments of economic, social, cultural, ecological, environmental, and political factors (David, 2004). The purpose underlying this stage is to investigate the impacts of external factors that affect the development of knowledge and science in a society in an attempt to discover and identify the opportunities and threats that face the national scientific system. Opportunities, in this context, may be defined as the whole range of facilities and capacities available in the external environment that, directly or indirectly, influence the performance of the scientific system. Threats are those factors in the external environment that may contribute, either directly or indirectly, to the inefficiency of the system. Based on the present research, the following opportunities and threats are found to be involved:

Table 3

Opportunities

Opportunities

1 Development and availability of IT resources

2 Concentration on knowledge-based economy in the $4^{\text {th }}$ and $5^{\text {th }}$ national development plans

Rapid scientific growth and its global recognition

Enthusiasm shown by the youths for learning

Potential demand on both domestic and regional levels for science and research products

Special focus on software movement and proliferation of science

Possibility to learn from experiences by successful nations

Increasing women's participation in graduate programs

Motivation on the part of top level managers and officials to reform the national science and technology system

The richness of the Iranian history and culture in science

Islamic culture and teachings that encourages learning

The vast number of Iranian scientists both inside Iran and abroad 
Table 4

Threats

\begin{tabular}{|c|c|}
\hline & Threats \\
\hline 1 & Low relevance of programs offered by the Department of Education and at higher education centers to scientific and innovation demands \\
\hline 2 & Inefficiency of management structures and motivational models \\
\hline 3 & $\begin{array}{l}\text { Inadequate organizational structure of science and technology development centers and inadequacy of administrative and steering research } \\
\text { bodies }\end{array}$ \\
\hline 4 & Low importance attached to the utilization of research findings in the process of policy making for science \\
\hline 5 & The low profile of Iranian expatriate scientists in domestic research activities \\
\hline 6 & The increasing trend in brain drain \\
\hline 7 & Lack of adequate incentives for young scientists \\
\hline 8 & Inadequate investment in research \\
\hline 9 & Economic sanctions and boycotts by western countries on importing new technologies \\
\hline 10 & The inadequate share of private sector in research \\
\hline 11 & Public preference for imported technologies over indigenous ones \\
\hline 12 & The fast trend in development of new technologies that requires extensive infrastructural facilities for competitiveness \\
\hline 13 & The lower attractiveness of scientific activities compared to other businesses \\
\hline 14 & The wide gap in technological development between Iran and western countries \\
\hline 15 & Lack of balance between advances made in science and new technologies developed \\
\hline 16 & Limited number of professional researchers \\
\hline
\end{tabular}

\subsubsection{Final analysis of the factors involved in proper development of science and technology}

For the ultimate analysis of the factors, the two categories of internal (weaknesses and strengths) and internal (threats and opportunities) factors were used to set up a Table consisting of four columns for factors, weights, scores, and weight scores. Column 1 included the most significant weaknesses, strengths, threats, and opportunities facing the system.

In Column 2, weights (from 1 for the most significant to zero for the least significant) are assigned to each of these factors based on their likely impacts on the current strategic state of the system. The weights are, in turn, derived from common knowledge about these factors and the analyses of the current state of the system so that higher weights designate greater impact on the current and future status of the system (the sum of weights in Column 2 will be equal to 1 irrespective of the number of factors). In Column 3, scores are assigned to each factor based on its significance and the current state of the system. Scores range from 5 (very good) to 1 (poor). Again, scoring is based on common knowledge about these factors and the analyses of the current state of the system.

The scoring system is expected to reflect the response of the system to external factors. Column 4 includes weight scores as the product of weight (Column 2) by score (Column 3) for each factor. The average weight score will be equal to 3 .

Finally, the weight scores are severally added up in Column 4 to obtain the overall weight scores for the two categories of internal and external factors. The overall weight score represents the behavior of the system in reaction to all the factors and potential forces in the surrounding environment. Typically, the average weight score for each category is equal to 3 (Hunger and Weellen, 1384, 2005: 90-92). Total weight scores greater than the average value represent higher significance while lower values represent less significance.

\subsubsection{Results of internal factors analysis (IFAS)}

The internal factors were organized within the categories of the system's weaknesses and strengths. For this purpose, use was made of the ranking system based on the significance level of each factor and their impacts (Ebrahimzadeh and Aghasizadeh, 1388 (2009: 117) on the development of science and technology in Iran. The results are summarized in Table 5. From the viewpoint of the respondents in this research, the most significant strengths that Iran's development in science and technology has benefited from are in a descending order: Availability of infrastructure for access to information networks (or connectivity), which ranked first with a weight score of 0.56 . This strength is regarded as the most important index of scientific development in Iran into which the state has directed great efforts but still needs to make more investments. 
Table 5

Results of internal factors analysis (Strengths)

\begin{tabular}{|c|c|c|c|}
\hline Strengths & Weight & Score & Weight score \\
\hline Availability of infrastructure for access to information networks (connectivity) & 0.14 & 4 & 0.56 \\
\hline Business incubators and S\&T parks established & 0.12 & 4 & 0.48 \\
\hline Availability of young, talented and educated work force & 0.11 & 4 & 0.44 \\
\hline Rapid increase in the number of ISI papers & 0.095 & 4 & 0.38 \\
\hline Availability of natural resources required for research and scientific production & 0.082 & 4 & 0.328 \\
\hline Availability of essential research facilities and equipment & 0.08 & 3 & 0.24 \\
\hline Availability of industry-based research centers & 0.072 & 3 & 0.216 \\
\hline The large number of universities and research institutes & 0.063 & 3 & 0.189 \\
\hline Increasing faculty members and researchers in the higher education sector & 0.062 & 3 & 0.186 \\
\hline Increasing number of graduate programs & 0.051 & 2 & 0.102 \\
\hline Incentive plans and awards for publishing papers in domestic and international journals & 0.043 & 2 & 0.086 \\
\hline The vast number of academic journals published in Iran & 0.04 & 1 & 0.04 \\
\hline The great number of conferences and scientific events organized inside Iran & 0.032 & 1 & 0.032 \\
\hline TOTAL & 1 & & 3.279 \\
\hline
\end{tabular}

Second is the establishment of knowledge-based infrastructure facilities such S\&T parks and business incubators which scored a weight score of 0.48 . This objective has been realized in a number metropolitan cities and major universities, which has naturally led to concentrated research activities with expectedly positive results. The increasing number and availability of educated youths ranks third with a weigh score of 0.44 . Iran is among the few countries with a large population of educated and young work force. The gifted and talented youths among these form a considerable portion which warrants special plans for their optimal contribution. Table 6 presents the results of the internal factors (weaknesses) analysis:

\section{Table 6}

\section{Results of internal factors analysis (weaknesses)}

\begin{tabular}{|c|c|c|c|}
\hline Weaknesses & Weight & Score & Weight score \\
\hline Lack of strategic plans for the science and technology sector & 0.093 & 4 & 0.372 \\
\hline Inadequate importance attached to meritocracy in appointing managers & 0.09 & 4 & 0.36 \\
\hline Precedence of requirements with face value (such as degrees) over real academic competence & 0.082 & 4 & 0.328 \\
\hline Poor relations among public departments and academic centers & 0.071 & 4 & 0.284 \\
\hline Failure to foster a research-based educational system by the Department of Education & 0.07 & 4 & 0.28 \\
\hline Uselessness and infeasibility of most research results & 0.065 & 4 & 0.26 \\
\hline Brain drain & 0.065 & 3 & 0.195 \\
\hline Inadequate number of competent and skilled managers to direct research projects of real value & 0.063 & 3 & 0.189 \\
\hline Low importance attached to the hiring and keeping of efficient and skilled work force & 0.055 & 3 & 0.165 \\
\hline Failure to use international experiences gained in developing scientific development programs & 0.05 & 3 & 0.15 \\
\hline Lack of proper local and indigenous models for the management of academic centers & 0.045 & 3 & 0.135 \\
\hline Inadequate remuneration and the low social status of researchers & 0.04 & 3 & 0.12 \\
\hline Lack of an appropriate performance evaluation and surveillance system & 0.035 & 2 & 0.07 \\
\hline Inadequate commercialization of research findings & 0.03 & 2 & 0.06 \\
\hline Predominance of a quantitative over a qualitative attitude to research & 0.025 & 2 & 0.05 \\
\hline Bureaucracy and poor administrative procedures and structure in research centers & 0.025 & 2 & 0.05 \\
\hline Impossibility of cooperation and resource sharing with progressive nations & 0.021 & 2 & 0.042 \\
\hline Nonexistence of an accountable body in charge of national statistics & 0.02 & 1 & 0.02 \\
\hline Inadequate concern for and lack of interest in research activities by the private sector & 0.02 & 1 & 0.02 \\
\hline Over-expectation from and overestimation of higher education for scientific development & 0.02 & 1 & 0.02 \\
\hline Greater importance given to individual work rather group work & 0.015 & 1 & 0.015 \\
\hline Poor understanding of developments in the surrounding environment & 0.01 & 1 & 0.01 \\
\hline TOTAL & 1 & & 3.175 \\
\hline
\end{tabular}

It is clear from Table 6 that lack of proper strategic plans for the science and technology sector with a weight score of 0.372 ranks first among the weaknesses. Obviously, an appropriate approach must be adopted for developing an exhaustive and all-embracing strategic plan that includes short-term, midterm, and long-term programs for execution. Low credit given to merits in management appointments had a weight score of 0.36 and ranked second among the weaknesses. Indeed, this is an important problem in the administrative and management system of Iran despite the many recommendations by top level leaders of the society and repeated advice by Iranian thinkers. It seems an approach is needed for resolving this problem that addresses the fundamentals of our administrative system. Precedence of degrees over real scientific competence with a weight score of 0.328 ranked third. It is unfortunate that most universities are being driven toward quantitative development by everincreasing enrollment with little or no heed paid to the educational content and quality. 


\subsection{External Factors Analysis}

The external factors were organized within the categories of the system's opportunities and threats. For this purpose, use was made of the ranking system based on the significance level of each factor and their impacts (Ebrahimzadeh \& Aghasizadeh, 2009) on the development of science and technology in Iran. The results are summarized in Table 7 below:

\section{Table 7}

Results of external factors analysis (opportunities)

\begin{tabular}{|c|c|c|c|}
\hline Opportunities & Weight & Score & Weight score \\
\hline Development and availability of IT resources & 0.152 & 4 & 0.0608 \\
\hline Concentration on knowledge-based economy in the $4^{\text {th }}$ and $5^{\text {th }}$ national development plans & 0.131 & 4 & 0.524 \\
\hline Rapid scientific growth and its recognition on the global scale & 0.122 & 4 & 0.488 \\
\hline The eagerness and enthusiasm shown by the young generation for learning & 0.11 & 4 & 0.44 \\
\hline Potential demand on both domestic and regional levels for science and research products & 0.097 & 4 & 0.388 \\
\hline Special focus on the software movement and proliferation of science & 0.078 & 3 & 0.234 \\
\hline Possibility to learn from experiences by successful nations & 0.066 & 3 & 0.198 \\
\hline Increasing participation of women in graduate programs & 0.061 & 3 & 0.183 \\
\hline $\begin{array}{l}\text { Motivation on the part of top level managers and official to reform the national science and technology } \\
\text { system }\end{array}$ & 0.052 & 2 & 0.104 \\
\hline The rich Iranian history and culture in science & 0.05 & 2 & 0.1 \\
\hline The rich Islamic culture that encourages learning & 0.045 & 1 & 0.09 \\
\hline The vast number of Iranian scientists both inside Iran and abroad & 0.036 & 1 & 0.036 \\
\hline Total & 1 & & 3.393 \\
\hline
\end{tabular}

Obviously, the factor named 'IT development' has the highest weight score of 0.608 and thus ranks first among the opportunities. This is, in fact, the most important index for scientific development in any nation. Iran has put great efforts into developing the IT infrastructure but more efforts and investments are required to fill in or to reduce the existing gap between the present state of Iran and that observed in progressive states. The second factor in this ranking system is the focus on knowledge-based economy as mandated by the $4^{\text {th }}$ and $5^{\text {th }}$ national development plans. The weight score for this factor is 0.524 which indicates the great role to be played by science and technology in generating wealth and reforming the economic structure. These objectives may be achieved by executing short-term programs. Ranking third among the opportunities, 'rapid trend in scientific development and its recognition on the global scale' won a weight score of 0.488 . However, efforts are needed to boost development and progress in this field to forge an Iranian model and example for other developing countries to follow. Table 8 summarizes the analytical results of the threats.

\section{Table 8}

Results of external factor analysis (Threats)

\begin{tabular}{|c|c|c|c|}
\hline Threats & Weight & Score & Weight score \\
\hline $\begin{array}{l}\text { Low relevance of programs offered by the Department of Education and higher education centers to scientific } \\
\text { and innovation demands }\end{array}$ & 0.115 & 4 & 0.46 \\
\hline Inefficiency of management structures and motivational models & 0.105 & 4 & 0.42 \\
\hline $\begin{array}{l}\text { Inadequate organizational structure of science and technology development centers and inadequacy of } \\
\text { administrative and steering research bodies }\end{array}$ & 0.1 & 4 & 0.4 \\
\hline Low importance attached to the utilization of research findings in the process of policy making for science & 0.092 & 4 & 0.368 \\
\hline The low profile of Iranian expatriate scientists in domestic research activities & 0.081 & 4 & 0.324 \\
\hline The increasing trend in brain drain & 0.07 & 3 & 0.24 \\
\hline Lack of adequate incentives for young scientists & 0.067 & 3 & 0.201 \\
\hline Inadequate investment in research & 0.065 & 3 & 0.195 \\
\hline Economic sanctions and boycotts for importing new technologies by western countries & 0.055 & 3 & 0.165 \\
\hline Inadequate participation and contribution in research by the private sector & 0.055 & 3 & 0.165 \\
\hline Public preference for imported technologies over indigenous ones & 0.045 & 2 & 0.09 \\
\hline $\begin{array}{l}\text { The fast trend in the development of new technologies that requires extensive infrastructural facilities for } \\
\text { competitiveness }\end{array}$ & 0.038 & 2 & 0.076 \\
\hline The lower attractiveness of scientific activities compared to other businesses & 0.037 & 2 & 0.074 \\
\hline The wide gap in technological development between Iran and western countries & 0.035 & 1 & 0.035 \\
\hline Lack of balance between advances made in science and new technologies developed & 0.025 & 1 & 0.025 \\
\hline Limited number of professional researchers & 0.015 & 1 & 0.015 \\
\hline Total & 1 & & 3.088 \\
\hline
\end{tabular}

Clearly, the irrelevance of educational programs to demands for science and innovation ranks first with a weight score of 0.46 . This means that revisions are required to plan the educational system in such a manner that it will be able to tailor for the emerging demand for more professionals. This has the additional advantage that the rate of unemployment among the youths with university degrees will 
reduce. Next item is associated with the inadequacy of management systems and motivational provisions with a weight score of 0.42 . To lift this threat, fundamental provisions and measures are required to deploy efficient management systems and managers with adequate incentives and motivation for engagement by the youths in scientific and technological development. The poor organizational structure in administrative systems of science and research centers had a weight score of 0.4 and, thus, ranked third among the threats. Rigorous structures are required for the evaluation science and technology development indicators that are simultaneously capable of strengthening the administrative system in research centers.

\subsection{Analysis of strategic factors}

According to the model used in the present study, the Tables presenting results of external and internal factors analyses are used along with their interactions to identify the most significant strategic factors involved in the desired knowledge-based development for the case in question, i.e. Iran. What is indeed expected to emerge as a result of this process for decision makers is a reduced number of factors (strengths, weaknesses, opportunities, and threats). The process involves transferring factors with the highest weights to Tables of Strategic Factors (Hunger \& Willen, 2007. This will allow researchers and decision-makers to revisit these factors and to make new judgments about the weights assigned. The final results for the present case under investigation are presented in Table 9 below:

\section{Table 9}

Results of Strategic Factors Analysis

\begin{tabular}{|c|c|c|c|c|c|c|}
\hline \multirow{2}{*}{ Factor } & \multirow{2}{*}{ weight } & \multirow{2}{*}{ Score } & \multirow{2}{*}{$\begin{array}{l}\text { Weight } \\
\text { score }\end{array}$} & \multicolumn{3}{|c|}{ Planning } \\
\hline & & & & Short-term & Mid-Term & Long-Term \\
\hline $\begin{array}{l}\text { S1= Availability of infrastructural facilities for access to information } \\
\text { networks (Connectivity) }\end{array}$ & 0.14 & 4 & 0.56 & & & \\
\hline S2= Establishment of S\&T parks \& Incubators & 0.12 & 4 & 0.48 & & & \\
\hline S3= Availability of young, educated and talented work force & 0.11 & 4 & 0.44 & & & \\
\hline W1= Lack of strategic plans for the science \& technology sector & 0.093 & 4 & 0.372 & & & \\
\hline W2= Failure to consider merits in selecting managers & 0.09 & 4 & 0.36 & & & \\
\hline W3= Preference and precedence of degree to content and competence & 0.082 & 4 & 0.328 & & & \\
\hline O1= Development of IT \& Internet facilities & 0.152 & 4 & 0.0 .608 & & & \\
\hline $\mathrm{O} 2=$ Focus on knowledge-based economy in the $4^{\text {th }} \& 5^{\text {th }}$ development plans & 0.131 & 4 & 0.524 & & & \\
\hline $\begin{array}{l}\text { O3= Rapid trend in the national scientific development and its global } \\
\text { recognition }\end{array}$ & 0.122 & 4 & 0.488 & & & \\
\hline T1 = Poor relevance of educational programs to national demands & 0.115 & 4 & 0.46 & & & \\
\hline $\mathrm{T} 2=$ Inefficiency of management and motivational systems and provisions & 0.105 & 4 & 0.42 & & & \\
\hline $\begin{array}{l}\text { T3= Poor scientific backbone and inadequacy of administrative systems for } \\
\text { research and scientific development }\end{array}$ & 0.1 & 4 & 0.4 & & & \\
\hline
\end{tabular}

We can now develop different competitive/aggressive, diversifying, revisionary, and reactive strategies by determining the interaction effects of these factors (Behzadfar \& Zamanian, 2008).

\section{Development of strategies}

\subsection{Competitive/aggressive strategies (so)}

This approach focuses on the internal strengths and external opportunities. The specific strategies proposed include:

- Developing a basic framework for the uniformly-distributed IT and Internet connectivity across the nation;

- Creating knowledge-based infrastructure such as S\&T parks and incubators as may be required in order to achieve a knowledge-based society that will ensure a powerful, dynamic, and developed state;

\subsection{Diversifying Strategies (st)}

The diversification approach concentrates on the internal strengths and external threats. The proposed strategies include: 
- Directing efforts at creating a balance between the demand for professionals and the number trained at universities and optimum exploitation of the educated youths towards achieving basic development objectives;

- Structuring and empowering the national science \& technology system and the work force involved through creating the IT infrastructure and S\&T parks.

\subsection{Revisionary strategies (wo)}

While paying due heed to internal weaknesses, these strategies make every effort to take advantage of external opportunities toward development of science and technology. The proposed strategies include:

- Developing a strategic plan for the national innovation system by concentrating on a knowledgebased structure embracing for all the national issues and activities;

- Efforts directed toward attracting young and talented work force in the state's research management system to develop an Iranian successful model of scientific progress.

- Reactive strategies (wt)

This set of strategies focuses on removing the vulnerabilities of science and research in Iran and includes:

- Taking advantage of improved and enhanced relevance between the demands for educated work force and the number of graduates aimed at enhancing quality in scientific endeavors to overcome the thirst and preference for university degrees;

- Increasing the number of short-, mid-, and long-term plans in the innovation system; improving upon the management system; and increasing the number of applied research projects.

\section{Conclusions}

Fostering science and technology in any society naturally prepares the fertile ground for its sustainable and full-fledged development. Evidently, it is essential for a community to pave its way toward a knowledge-based society that will empower it to developed well-thought and science-based solutions to its many problems. Many nations have put their efforts into this, especially by developing the required economic systems and bodies. Iran has only recently turned to this approach for resolving its problems and obviously needs fundamental programs and plans to enhance the effectiveness of its efforts. The present research is an attempt toward this objective.

The results of the present study reveal that: The recently increased availability of IT infrastructure and resources with a weight score of 0.56 has the highest rank among the strengths while lack of strategic plans for the innovation system with a weight of 0.372 has the same rank among the weaknesses. Development of IT and Internet infrastructure with a weight score of 0.608 was found to rank first among the opportunities while poor relevance of the educational programs to the demands by the innovation system had a weight score of 0.46 , which puts it highest among the threats.

The most prominent strategies that were identified for implementation include: 1) Formulation of a basic framework for the development and uniform distribution of IT and Internet resources across the nation; 2) Establishment and maximum development of knowledge-based infrastructural facilities such S\&T parks, business incubators, S\&T corridors, and innovation clusters; 3) Directing efforts and investments towards the creation of a knowledge-based society to achieve the objectives of a dynamic, powerful, and developed nation-state; 4) Striking a balance between the demand for professionals and the number of university graduates; and finally, 5) Optimal participation of the educated youths in programs and schemes designed to achieve the basic national development objectives.

Based on the results obtained from this study, the following recommendations are made:

- Careful attention to and implementation of the major national plans related to the objective of knowledge-based development; these include the 20-year national vision plan, the general national 
policies regarding national scientific development, the $5^{\text {th }}$ national development plan, the national scientific roadmap, and the Act of knowledge-based firms Support.

- Preparing the conditions for increased participation and contribution of educated and dedicated work force in strategic scientific and research institutions along with close surveillance and evaluation of their performance.

- Application of the lessons learned by similar organizations and developed nations across the world with regard to their experiences in advancing their knowledge-based systems.

- Directing efforts toward improved quality and enhanced quantity regarding national scientific development.

- Establishing an efficient body in charge of evaluation and assessment of the performance of the knowledge-related institutions.

- Continued evaluation of science, technology, and innovation based on internationally recognized indices.

\section{References}

Ahmadi, A. et al. (2003). IT and its Applications, $1^{\text {st }}$ Ed., Tolid Danesh Publications, Tehran.

Ahmadvand, A., \& Rohani, A. (2007). Toward a knowledge-based Police. Journal of Police Sciences, 9(2), (In Persian).

Akhavan, P., \& Bagheri, R. (2010). Knowledge Management. Atinegar Publishers, Tehran.

Austin, L. (2011). Future Melbourne (Economic Development and Knowledge City) Committee Report, Office of Knowledge Capital (OKC) evaluation.

Bagheri, Kh., \& Sharafi Jam, M.R. (2009). Reflections on the concepts of knowledge and education in a knowledge-based society. Curriculum Studies Quarterly, 3(12). (In Persian).

Bahari, A. et al. (2010). Identification and prioritization of key factors involved in the success of Khorasan Razavi S\&T Park. S \& T Parks \& Incubators Quarterly, 8(30).

Bayat M. et al., (2011). Early realization of the scientific objectives of the 20-year national vision plan. Journal of Neshae EIm (Dissemination of Knowledge), 2(1).

Behzadfar, M., \& Zamanian, (2008). Strategic planning for promoting tourism with emphasis on best product: A case study of Neishabur city. International Journal of Iran Science \& Technology University, 19(6).

Carrillo, F. J. (2006). From transitional to radical knowledge-based development.Journal of Knowledge Management, 10(5), 3-5.

Carrillo, F. J. (2009). Demarcation and levels of analysis in knowledge based development. Journal of Knowledge Management, 13(5), 208-213.

Chou, P. B., \& Passerini, K. (2009). Intellectual property rights and knowledge sharing across countries. Journal of Knowledge Management, 13(5), 331-344.

Davarpanah, M.R. (2005), Information and Society, $1^{\text {st }}$ ed., Dabizesh Publishers, Tehran.

David, F. R. (2004). Strategic management: Concepts and cases. Prentice Hall.

Ebrahimzadeh, I., \& Aghasizadeh, A. (2009). Analysis of the factors involved in enhanced tourism in Chabahar beaches using the SWOT strategic model. Journal of Regional \& Urban Studies, 1(1), Summer Issue (In Persian).

Hanger, J. D., \& Willen, T. L. (2002). Fundamental of Strategic Management (S.M. A'rabi and D. Izadi, Trans.), $1^{\text {st }}$ ed., Cultural Research Bureau Publications, Tehran.

Hassanpour, H. et al. (2012). Identification and analysis of the factors involved in the preparedness of universities for the successful implementation of KM systems. S\&T Parks \& Incubators Quarterly, 8(30).

Hawkins, J. (2002). The Creative Economy. Penguin Press, London.

Hohn, S. (2010). Key factors for the success of knowledge cities in Germany: findings of an empirical study/ Faculty of Social Sciences and Economic Public Management, University of Applied Sciences Osnabrück Caprivistraße 30a 49076 Osnabrück, Germany.

http://www.innovationfordevelopmentreport.org/ papers/ICIrankings2010_11.pdf 
http://www.nationmaster.com/graph/eco_tec_acheconomy- technological-achievement 2012.

Lange, B., Kalandides, A., Wellmann, I., \& Krusche, B. (2010). New urban governance approaches for knowledge-based industries in multiplicities: Comparing two cases of large inner-city developments in Graz and Berlin. Journal of Place Management and Development, 3(1), 67-88.

Lerro, A., \& Schiuma, G. (2009). Knowledge-based dynamics of regional development: the case of Basilicata region. Journal of Knowledge Management,13(5), 287-300.

Mansouri, R. (2010). The Architecture of Science in Iran. Iran's Observatory, Sharif University of Technology.

Mehrdad, J. (2011). Details of Scientific Production Growth in Iran.

Moffett, S., McAdam, R., \& Parkinson, S. (2003). An empirical analysis of knowledge management applications. Journal of knowledge Management, 7(3), 6-26.

Mohayidin, M.G., et al. (2007). Application of knowledge management to enhance the performance of universities. Electronic Journal of Knowledge Management, 301-312.

Movahedi, F. (2008). Technology Quantification Measures; Economic Research. Proceedings of Iran's Central Bank.

Nemati, M.A. (2006). Knowledge management, culture and higher education. S\&T Parks and Incubators Quarterly, 7, 25-35, (in Persian).

Osareh, F., \& Ma'refat, R. (2005). Contributions by Iranian researchers to the global science production reported in MEDLINE. Journal of Rahyaft, No. 35 (in Persian).

Passerini, K., (2007). Knowledge-driven development indicators: still an eclectic panorama. Journal of Knowledge Management, 11(5), 115-128.

Paya A., \& Kalantarinezhad, R. (2010). A philosophical evaluation of and the policy-making indices of the impacts of the $4^{\text {th }}$ scientific and technological wave on culture and society: Critical-rational reflections. Journal of Science \& Technology Policies, 2(4).

Rashidi, E. (2008). Knowledge-based Society: The Fertile Ground for Innovation. Proceedings of the First National Conference on Creatology, TRIZ, and Management Engineering of Iranian Innovators \& the $1^{\text {st }}$ National Conference on Science Fiction and its Applications, Nov. 2008, Research Center for Innovatology.

Sabouri, A.A. (2012). Science Production in 2011 in Iran. Journal of Neshae Elm (Dissemination of Knowledge), 2(2).

Sadeghi, M. and K. Azarbayejani, 1385 (2006); 'The Role and Status of Knowledge-based Economy in Demand for Work Force in Iran'; J. of Iranian Economic Studies, No. 27.

Sayyedi, M., et al. (2007), Feasibility study of realizing a knowledge-based organization at the Shiraz branch of Islamic Azad University. New Horizons in Education Quarterly, 2(2).

Seif, M.H. et al. (2006). Systems and the future of knowledge management. Journal of Thinking, 171, Industrial Management Organization Publications.

Sheehan, P., \& Tegart, G. (1998). Working for the future: Technology and employment in the global knowledge economy. Victoria University Press, Melbourne.

The $4^{\text {th }}$ Economic, Social, and Cultural Development Plan of the I.R. Iran. (2005). Chapter 4: Knowledge-Based Development.

Wang, X., \& Lihua, R. (2006). Examining knowledge management factors in the creation of new city: Empirical evidence from Zhengdong New District, Zhengzhou, China. Journal of Technology Management in China, 1(3), 243-261.

Webster, A. (1991). Science, Technology, and Society. Macmillan, London.

WEF- Global Information Technology Report 2012.

Wheelen, T. L., \& Hunger, J.D. (1995). Strategic Management and Business Policy (5 ${ }^{\text {th }}$ ed.). Reading, MA: Addison-Wesley.

Worthington, L., \& Britton, C. (2006). The Business Environment (6 ${ }^{\text {th }}$ ed.). Pearson Education Limited.

Yousefinejad-Attari, M., \& Neishabouri-Jami, A. (2012). Implementation of SWOT Tables for S\&T parks and determination of the best approach for achieving objectives using the Fuzzy ANP, Journal of S\&T Parks and Incubators, 8, 30. 